\title{
Polyquad-Preserved Travoprost/Timolol, Benzalkonium Chloride (BAK)-Preserved Travoprost/Timolol, and Latanoprost/Timolol in Fixed Combinations: a Rabbit Ocular Surface Study
}

Hong Liang · Françoise Brignole-Baudouin · Aude Pauly · Luisa Riancho $\cdot$ Christophe Baudouin

Received: December 17, 2010 / Published online: March 17, 2011

(c) The Author(s) 2011. This article is published with open access at Springerlink.com

\section{ABSTRACT}

Introduction: The aim of this study was to use a validated acute rabbit model to test the toxicity of a novel formulation of fixed-combination travoprost $0.004 \%$ /timolol $0.5 \%$ ophthalmic solution, which contains the antimicrobial preservative polyquaternium-1 (PQ), compared with the commercial formulation of fixed combinations travoprost $0.004 \% /$ timolol $0.5 \%$ ophthalmic solution and latanoprost $0.005 \% /$ timolol $0.5 \%$ ophthalmic solution, which both contain the preservative

Hong Liang • Françoise Brignole-Baudouin • Aude Pauly • Luisa Riancho $\cdot$ Christophe Baudouin INSERM, UMR_S968, Paris, F-75012, France; UPMC Univ Paris 06, UMR_S968, Institut de la Vision, Paris, F-75012, France; and CNRS, UMR_S7210, Paris, F-75012, France

Françoise Brignole-Baudouin $(\bowtie)$

Laboratoire de Toxicologie, Faculté des Sciences Pharmaceutiques et Biologiques, Université Paris Descartes, 4 avenue de l'Observatoire, 75006 Paris, France. Email: francoise.brignole@inserm.fr

Hong Liang · Françoise Brignole-Baudouin · Aude Pauly • Christophe Baudouin

Centre Hospitalier National d'Ophtalmologie des Quinze-Vingts, INSERM-DHOS CIC 503, Paris,

F-75012, France benzalkonium chloride (BAK). Methods: Adult male New Zealand albino rabbits $(n=24)$ were randomly divided into four groups. Phosphatebuffered saline (PBS), travoprost/timolol PQ, travoprost/timolol BAK, or latanoprost/timolol BAK were instilled onto rabbit eyes one drop, 15 times at 5 minute intervals. The ocular surface reactions were investigated at hour 4 and day 1 using slit lamp examination; in-vivo confocal microscopy (IVCM) for cornea, limbus, and conjunctiva-associated lymphoid tissue (CALT); conjunctival impression cytology; and standard immunohistology in cryosections for detecting CD45+ infiltrating cells and MUC5AC-labeled cells. Results: Travoprost/timolol PQ was better tolerated than travoprost/timolol BAK or latanoprost/timolol BAK. This improved tolerance was evident via clinical observation under slit lamp, IVCM in different layers of the cornea and conjunctiva, conjunctival impression cytology of superficial epithelium aspects, and immunohistochemistry for inflammatory infiltration of CD45+ cells in the cornea and goblet cell distribution. Travoprost/timolol PQ was similar to PBS in regards to in-vivo findings, the Draize test for ocular irritation, and epithelial and limbal aspects as evaluated with IVCM. Treatment with either travoprost/timolol 
PQ or PBS produced no obvious inflammatory infiltration inside and outside the CALT follicles, yielded similar IVCM toxicity scores and CD45+ cell counts, and eyes treated with either solution had normal goblet cells. Conclusion: The fixed combination of travoprost/timolol with $0.001 \%$ PQ had decreased ocular surface toxicity relative to the BAK-containing solutions. The potential benefit to the human ocular surface with oncedaily dosing needs to be evaluated clinically.

Keywords: benzalkonium chloride; Duotrav; in vivo; latanoprost; ocular surface toxicity; polyquad; timolol; travoprost; Xalacom

\section{INTRODUCTION}

Prostaglandins are the first-line monotherapy for lowering intraocular pressure (IOP) in patients with glaucoma and ocular hypertension because of their efficacy, favorable side effect profile, and once-daily administration. Nonetheless, many patients require multiple ophthalmic IOP-lowering medications in order to control their intraocular pressure. One study of 4444 newly diagnosed patients with glaucoma revealed that approximately $20 \%$ required adjunctive therapy, irrespective of the initial prostaglandin analog monotherapy. ${ }^{1}$ Likewise a retrospective analysis found that approximately $20 \%$ of 12,202 patients with glaucoma treated with prostaglandin monotherapy required adjunctive therapy during the first year of treatment. ${ }^{2}$

Using more than one ophthalmic medication is difficult for many patients. Improper time adherence to the instillation of the second medication is common, and can be a safety issue. ${ }^{3}$ Even in a clinical trial where the timing of dosing is monitored, and where the patients are reminded of the dosing time electronically, patients have difficulty taking the medication at the appropriate time. ${ }^{3}$ Also, dosing errors related to underdosing or overdosing are more common in patients taking two ophthalmic medications. ${ }^{3}$

Instillation of several benzalkonium chloride (BAK)-preserved ophthalmic medications is another potential safety concern. Studies show that BAK is associated with decreased tear film stability, worsening of dry eyes, inflammatory cell infiltration, superficial punctate keratitis, blepharitis, and eyelid eczema. ${ }^{4-7}$ The BAK in eye drops can cause or worsen ocular surface disease, and patients with glaucoma taking several BAK-containing drops have a higher risk of developing ocular surface disease. ${ }^{8,9}$ Reportedly, 48\%-59\% of patients with glaucoma or ocular hypertension have symptoms of ocular surface disease in at least one eye..$^{8,9}$ Use of fixedcombination products can reduce many of these safety concerns.

Even though topical ocular fixed combinations reduce the exposure to the antimicrobial preservatives, all currently available prostaglandin-analog fixed combinations contain BAK. For example, travoprost $0.004 \%$ / timolol 0.5\% ophthalmic solution (travoprost/ timolol BAK, DuoTrav ${ }^{\circledR}$; Alcon Laboratories, Inc., Fort Worth, TX, USA) contains $0.015 \%$ BAK, and latanoprost $0.005 \% /$ timolol $0.5 \%$ ophthalmic solution (latanoprost/timolol BAK, Xalacom ${ }^{\circledR}$; Pfizer, New York, NY, USA) contains 0.02\% BAK. Additional benefits may result if products contain a less toxic antimicrobial preservative. To this end, travoprost/timolol BAK has been reformulated, and BAK has been replaced with the polymeric quaternary ammonium antimicrobial preservative polyquaternium-1 (PQ; Polyquad ${ }^{\circledR}$; Alcon Laboratories UK, Ltd., Hemel Hempstead, Hertfordshire, UK). PQ has been successfully used in contact lens solutions, artificial tear substitutes, and an ocular hypertensive medication. ${ }^{10-12}$ According to ophthalmic research in animal models, PQ 
is safer for the ocular surface than BAK. ${ }^{10,13,14}$ In rabbits, PQ produced less corneal staining than BAK, and produced only superficial epithelial damage. ${ }^{14}$ Even at high doses, PQ was much less toxic than BAK in an acute rat model with slitlamp examination, fluorescein, and red phenol tests, impression cytology collection, and corneal in-vivo confocal microscopy (IVCM) analyses. ${ }^{10}$

The purpose of this study was to assess the toxicological profile of travoprost/timolol preserved with PQ versus travoprost/timolol BAK, and latanoprost/timolol BAK in a validated acute rabbit model. ${ }^{15} \mathrm{~A}$ set of new experimental tools, such as corneal IVCM, conjunctival impression cytology (CIC), and immunohistology, were used.

\section{METHODS}

Male albino New Zealand rabbits (CEGAV S.S.C.; Saint-Mars-d'Egrenne, France) weighing approximately $2.5 \mathrm{~kg}$ were anesthetized with a mixture of ketamine (35 mg/kg; Imalgène ${ }^{\circledR} 500$; Merial, Lyon, France), and xylazine $(5 \mathrm{mg} / \mathrm{kg}$; Rompun ${ }^{\circledR}$; Bayer, Puteaux, France). After the animals were anesthetized and before all experiments, the ocular surface integrity was examined by slit lamp microscopy. Twentyfour rabbits were randomly divided into four groups. Each group was composed of 12 eyes of six rabbits: six eyes for assessments 4 hours after treatment ( $\mathrm{H} 4)$, and six eyes for assessments 1 day after treatment (D1). All rabbits were used for clinical observations, IVCM observations, and CIC, and were later killed for immunohistological procedures. Data were interpreted and scored in a blind manner. All experiments were conducted in accordance with the Association for Research in Vision and Ophthalmology's (ARVO) Statement for the Use of Animals in Ophthalmic and Vision Research.
Four sterile compounds were evaluated: (1) phosphate-buffered saline (PBS; Eurobio, Les Ulis, France); (2) travoprost/timolol PQ, preserved with PQ 0.001\% (Alcon Laboratories); (3) travoprost/timolol BAK, preserved with $0.015 \% \mathrm{BAK} ;$ (4) latanoprost/timolol BAK, preserved with $0.02 \%$ BAK. Sterile pipette tips were used to instill $50 \mu \mathrm{l}$ drops, 15 times at 5 minute intervals to the rabbit eyes. The first instillation was considered time zero.

\section{In-Vivo Findings and Draize test}

Using slit lamp microscopy, the eyes were examined at $\mathrm{H} 4$ and D1 for ocular irritation, and scored according to a weighted scale for grading the severity of ocular lesions. The scale was modified from the Draize test, as used in previous studies. ${ }^{16-18}$ Briefly, the degree of hyperemia, swelling of the conjunctiva (chemosis) and tearing, areas of cornea opacity, increased prominence of folds, and congestion of the iris were evaluated, with a possible maximum combined score of 110 . Corneal opacity and the increased prominence of folds and congestion of the iris were always negative (score $=0$ ). The only variables with positive observations (chemosis, tearing, and redness) are presented in the results section. Chemosis was rated 0 to 3 , with $0=$ no chemosis and $3=$ obvious chemosis with more than half of the eyelid closed. Tearing was rated 0 to 3 , with $0=$ no tearing and $3=$ tearing covering the entire eyeball. Redness was rated 0 to 3 , with $0=$ normal blood vessels and $3=$ diffuse beefy red. Thus the maximum possible score for the positive observations was 9 .

\section{IVCM Observation and IVCM-Conjunctiva- Associated Lymphoid Tissues Scale}

As in previous animal studies, the laser scanning IVCM Heidelberg retina tomograph (HRT) II/ 
Rostock cornea module (Heidelberg Engineering GmbH, Heidelberg, Germany) was used to examine the entire ocular surface. ${ }^{10,16-18}$ For all eyes, at least 10 confocal microscopic images of each layer in the conjunctiva-associated lymphoid tissues (CALT)/limbus/cornea were analyzed. The final scores were the averages of both eyes of three animals $(n=6)$. In order to quantify the observed patterns, the IVCM-CALT scale was used to quantify the whole ocular surface toxicity as shown in Table 1.

\section{CIC Collection}

CIC specimens were collected by techniques previously described. ${ }^{18,19}$ Briefly, two nitrocellulose membrane filters (Millipore Corporation, Bedford, MA, USA) were applied

Table 1. In-vivo confocal microscopy (IVCM) scoring for evaluating ocular toxicity.

\begin{tabular}{|c|c|c|c|}
\hline \multirow[b]{2}{*}{ Tissue } & \multicolumn{2}{|r|}{ Ocular surface damage } & \multirow{2}{*}{$\begin{array}{l}\text { IVCM } \\
\text { score }^{*}\end{array}$} \\
\hline & Property & Toxicity observed & \\
\hline \multirow{5}{*}{$\begin{array}{l}\text { Superficial epithelium } \\
\text { (max } 10 \text { points) }\end{array}$} & Desquamation & Partial & 2 \\
\hline & & Total important & 4 \\
\hline & Shape/size & $\begin{array}{l}\text { Anisocytosis, microcytosis, macrocytosis, irregular shape, } \\
\text { edematous cells, swollen cells, loss of cell borders }\end{array}$ & 2 \\
\hline & Reflectivity & $\begin{array}{l}\text { Abnormal reflectivity patterns: hyper-reflective cells, } \\
\text { nuclei visible in hyper-reflective cells or not }\end{array}$ & 2 \\
\hline & Inflammation & Presence of inflammatory infiltration & 2 \\
\hline \multirow{5}{*}{$\begin{array}{l}\text { Basal epithelium } \\
\text { (max } 10 \text { points) }\end{array}$} & Disorganization & $\mathrm{N} / \mathrm{A}$ & 2 \\
\hline & Inflammatory infiltration & $0<$ slight $<50$ cells $/ \mathrm{mm}^{2}$ & 2 \\
\hline & & $50<$ mild $<100$ cells $/ \mathrm{mm}^{2}$ & 4 \\
\hline & & $100<$ moderate $<200$ cells $/ \mathrm{mm}^{2}$ & 6 \\
\hline & & Severe $>200$ cells $/ \mathrm{mm}^{2}$ & 8 \\
\hline \multirow{5}{*}{$\begin{array}{l}\text { Anterior stroma } \\
\text { (max } 10 \text { points) }\end{array}$} & Disorganization & $\mathrm{N} / \mathrm{A}$ & 2 \\
\hline & Inflammatory infiltration & $0<$ slight $<50$ cells $/ \mathrm{mm}^{2}$ & 2 \\
\hline & & $50<$ mild $<100$ cells $/ \mathrm{mm}^{2}$ & 4 \\
\hline & & $100<$ moderate $<200$ cells $/ \mathrm{mm}^{2}$ & 6 \\
\hline & & Severe $<200$ cells $/ \mathrm{mm}^{2}$ & 8 \\
\hline \multirow{7}{*}{$\begin{array}{l}\text { Limbus and conjunctiva } \\
\text { ( } \max 10 \text { points) }\end{array}$} & Presence of capillary bud & & \\
\hline & from limbal vessels (trend to & & \\
\hline & neovascularization) & $\mathrm{N} / \mathrm{A}$ & 2 \\
\hline & Presence of inflammatory & $0<$ slight $<50$ cells $/ \mathrm{mm}^{2}$ & 2 \\
\hline & infiltrates, rolling in limbal & $50<$ mild $<100$ cells $/ \mathrm{mm}^{2}$ & 4 \\
\hline & vessel/conjunctiva zone & $100<$ moderate $<200$ cells $/ \mathrm{mm}^{2}$ & 6 \\
\hline & & Severe $>200$ cells $/ \mathrm{mm}^{2}$ & 8 \\
\hline \multirow{4}{*}{$\begin{array}{l}\text { CALT inside }+ \text { outside } \\
\text { the follicle } \\
\text { (max } 8 \text { points) }\end{array}$} & Inflammatory infiltration & $0-100$ cells $/ \mathrm{mm}^{2}$ & $0 / 1$ \\
\hline & & $100-500$ cells $/ \mathrm{mm}^{2}$ & 2 \\
\hline & & $500-1000$ cells $/ \mathrm{mm}^{2}$ & 3 \\
\hline & & $>1000$ cells $/ \mathrm{mm}^{2}$ & 4 \\
\hline
\end{tabular}

${ }^{*}$ Maximum score $=48$.

$\mathrm{CALT}=$ conjunctiva-associated lymphoid tissues; $\mathrm{N} / \mathrm{A}=$ not applicable. 
onto the superior bulbar conjunctiva and then dipped into tubes containing $1.5 \mathrm{~mL}$ cold PBS with $4 \%$ paraformaldehyde (4\% PFA). The membranes were then washed in distilled water, dehydrated in ethanol, stained with cresyl violet solution (1\%, \# 5235, Merck, Fontenaysous-Bois, France) for 30 minutes, air-dried, and mounted in Eukitt medium (CML, Nemours Cedex, France). The CIC specimens were photographed with a Leica ${ }^{\circledR}$ DM5000 fluorescent microscope (Leica Microsystems, Wetzlar, Germany), and all the images were taken using magnification of $\times 200$.

The morphology of the CIC specimen was scored according to a modified Nelson classification, thereby assigning grades to the ocular surface. ${ }^{20}$ Morphological parameters such as epithelial cell changes, inflammatory infiltration, and density of goblet cells were scored 0 to 3 , with $0=$ normal $/$ none and $3=$ abundant $/$ massive. The maximum score was 30 .

\section{Cryosections and Immunohistology}

Two rabbits in each group were euthanized with a lethal dose of pentobarbital at selected time points. Enucleated eyes were fixed in $4 \%$ PFA and embedded in OCT Embedding Matrix (CellPath Ltd., Newtown, UK). The $10 \mu \mathrm{m}$ cryosections were incubated with mouse antibodies directed against rabbit CD45 (1:50; CBL1412; Cymbus Biotechnology, Chandlers Ford, UK) to detect inflammatory cell infiltration, or directed against MUC-5AC (donated by Jacques Bara, INSERM, University Paris 6, Paris, France) to detect goblet cells. Sections were stained with secondary antibody (488 goat anti-mouse; Alexa Fluor $^{\circledR}$; Molecular Probes; Eugene, OR, USA) and propidium iodide.

Images were digitized using a Leica DM5000 fluorescent microscope equipped with a digital camera and image analysis software. Immunohistological data from two different

rabbit eyes in three or more different areas, and from a length of $500 \mu \mathrm{m}$ of cornea or conjunctiva (= one field for counting), were analyzed in a masked fashion.

\section{Statistical Analysis}

Results are expressed as mean \pm standard error (SEM). The groups were compared using twoway analysis of variance (ANOVA) followed by multiple pair-wise comparisons using Fisher's method adjustment (Statview Version 5; SAS Institute Inc., Cary, NC, USA).

\section{RESULTS}

\section{In-Vivo Findings}

Eyes treated with PBS (Figure 1A) had no obvious irritation on the ocular surface. Travoprost/

Figure 1. Microphotographs of typical clinical features at hour 4 (H4). (A) Phosphate buffered saline (PBS) induced no hyperemia, chemosis, or secretions on the conjunctiva.

(B) Travoprost/timolol polyquarternium (PQ) induced very slight redness with no chemosis or secretions on the conjunctiva. (C) Travoprost/timolol benzalkonium chloride (BAK) induced conjunctival hyperemia with mild chemosis. (D) Latanoprost/timolol BAK induced diffuse hyperemia and chemosis on the conjunctiva compared with PBS.

\section{(A)}

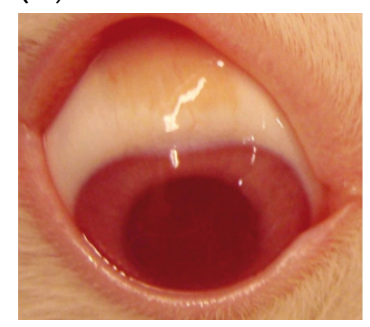

(C)

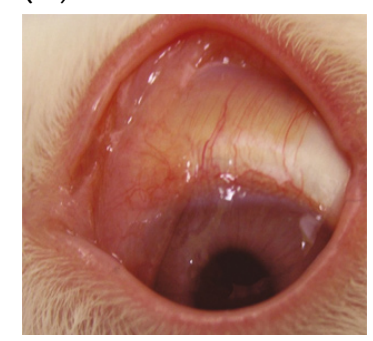

(B)

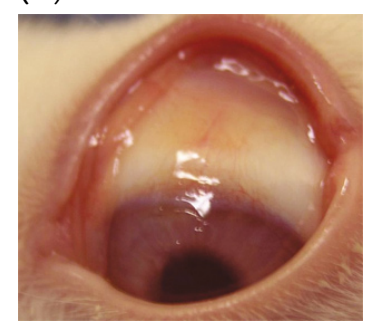

(D)

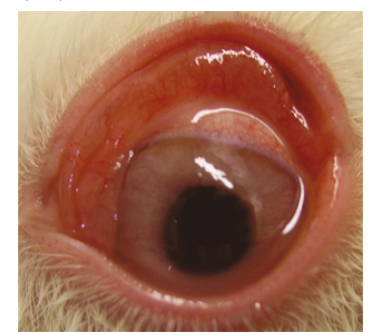


timolol PQ (Figure 1B) was also well tolerated, producing very slight redness without tearing, chemosis, or secretions. Travoprost/timolol BAK (Figure 1C) induced conjunctival hyperemia with slight chemosis. In contrast to Figure $1 \mathrm{~B}$, latanoprost/timolol BAK (Figure 1D) induced obvious diffuse hyperemia, tearing, and chemosis on the conjunctiva at H4 (4 hours after the first instillation or 2.75 hours after the last instillation).

\section{Draize Test}

At $\mathrm{H} 4$, the Draize test revealed that travoprost/ timolol PQ produced significantly less ocular irritation than travoprost/timolol BAK $(P<0.02)$ and latanoprost/timolol BAK $(P<0.02$; Figure 2$)$. Travoprost/timolol PQ induced a low Draize test score, which did not differ significantly from the

Figure 2. Modified Draize test scores to evaluate ocular irritation (mean \pm standard error $[\mathrm{SEM}]$ ) at hour $4(\mathrm{H} 4)$ and day 1 (D1) in rabbit eyes ( $n=6$ eyes/time point); ${ }^{*} P<0.01$ vs. phosphate buffered saline (PBS); $\uparrow P<0.02$ vs. travoprost/timolol polyquarternium (PQ); $\neq P<0.02$ vs. travoprost/timolol benzalkonium chloride (BAK).

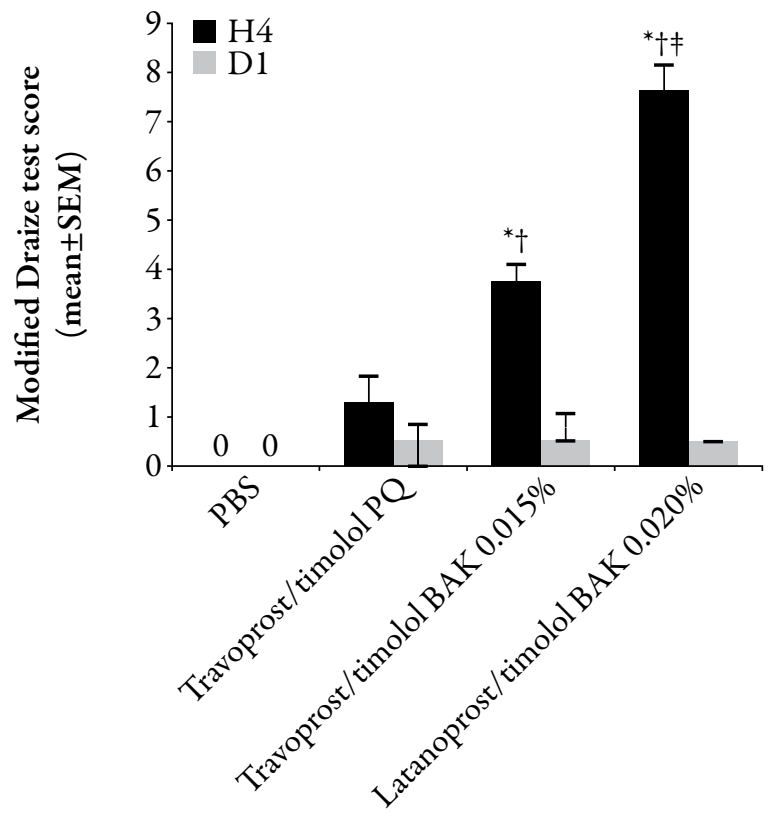

PBS score. Travoprost/timolol BAK presented a moderately elevated Draize score, which was significantly less than latanoprost/timolol BAK $(P<0.02)$, but significantly greater than PBS $(P<0.01)$, and travoprost/timolol PQ $(P<0.02)$.

At D1 (24 hours after the first instillation or 22.75 hours after the last instillation), the Draize scores decreased for all treatment groups. There were no significant differences between the treatments at D1 for the Draize measure of ocular irritation (Figure 2).

\section{IVCM and IVCM-CALT Scale}

\section{Surface Epithelium}

At H4, PBS-instilled (Figure 3A) rabbit eyes presented a surface epithelium with a regular mosaic appearance and brightly reflective nuclei. The eyes instilled with travoprost/timolol PQ (Figure 3B) had epithelial aspects that were similar to PBS-instilled eyes, with no important desquamation, normal cell shape and size, and no inflammatory infiltration. Travoprost/ timolol BAK (Figure 3C) induced moderate damage to the surface epithelium; showing partial desquamation, abnormal reflectivity patterns, and anisocytosis with irregular cell shape. Inflammatory cells were also occasionally observed. After instillations of latanoprost/ timolol BAK (Figure 3D), there was evidence of desquamation of the surface epithelium, and the remaining epithelial cells presented swelling, irregular cell shape, and anisocytosis aspects. Also, there was marked hyper-reflective inflammatory cell infiltration after instillation of latanoprost/timolol BAK.

At D1, the outcomes were similar to that at H4. PBS and travoprost/timolol PQ (Figure 4A-B) presented similar normal aspects of the surface epithelium. The travoprost/ timolol BAK (Figure 4C) and latanoprost/ timolol BAK (Figure 4D) groups again presented 
Figure 3. At hour 4 (H4) the corneal in-vivo confocal microscopy (IVCM) images of the rabbit corneal superficial epithelium (line 1), basal epithelium (line 2), limbus (line 3), and conjunctiva-associated lymphoid tissue (CALT) (line 4) after the applications of (A) phosphate-buffered saline (PBS), (B) travoprost/timolol polyquarternium (PQ), (C) travoprost/ timolol benzalkonium chloride (BAK), and (D) latanoprost/timolol BAK.

\begin{tabular}{|c|c|c|c|c|}
\hline & $\begin{array}{l}\text { (A) } \\
\text { PBS }\end{array}$ & $\begin{array}{c}\text { (B) } \\
\text { Travoprost/ } \\
\text { timolol PQ }\end{array}$ & $\begin{array}{c}(\mathrm{C}) \\
\text { Travoprost/ } \\
\text { timolol BAK } \\
0.015 \%\end{array}$ & $\begin{array}{c}(\mathrm{D}) \\
\text { Latanoprost/ } \\
\text { timolol BAK } \\
\mathbf{0 . 0 2 \%}\end{array}$ \\
\hline \multirow{3}{*}{\multicolumn{5}{|c|}{$\begin{array}{l}\text { Line } 1 \\
\text { Superficial epithelium } \\
\text { Depth: } 0 \mu \mathrm{m}\end{array}$}} \\
\hline & & & & \\
\hline & & & & \\
\hline \multicolumn{5}{|l|}{ Line 2} \\
\hline \multicolumn{5}{|l|}{ Basal epithelium } \\
\hline \multicolumn{5}{|l|}{ Depth: $10-15 \mu \mathrm{m}$} \\
\hline \multicolumn{5}{|l|}{ Line 3} \\
\hline \multicolumn{5}{|l|}{ Limbus } \\
\hline \multicolumn{5}{|l|}{ Depth: $10-30 \mu \mathrm{m}$} \\
\hline \multicolumn{5}{|l|}{ Line 4} \\
\hline \multicolumn{5}{|l|}{ CALT } \\
\hline Depth: $0-15 \mu \mathrm{m}$ & & & & \\
\hline
\end{tabular}

abnormalities, with partial desquamation, and hyper-reflectivity of the epithelium. However, in the latanoprost/timolol BAK and the travoprost/timolol BAK groups the inflammatory infiltration decreased (but not to normal levels) compared with $\mathrm{H} 4$, and inflammatory cells were occasionally observed.

\section{Basal Epithelium}

At H4, PBS (Figure 3A) and travoprost/timolol PQ (Figure 3B) both induced minimal levels $\left(<5\right.$ cells $\left./ \mathrm{mm}^{2}\right)$ of inflammatory cell infiltrates in the basal epithelium. Travoprost/timolol
BAK (Figure 3C) induced a moderate level of bright hyper-reflective inflammatory infiltrates $\left(62.3 \pm 7.3\right.$ cells $\left./ \mathrm{mm}^{2}\right)$. Latanoprost/ timolol BAK (Figure 3D) induced the greatest amount of inflammatory cell infiltration $\left(135.4 \pm 16.1\right.$ cells $\left./ \mathrm{mm}^{2}\right)$. As shown in Figure 4, the findings at D1 were similar to $\mathrm{H} 4$.

\section{Limbus}

At $\mathrm{H} 4$ and D1, normal limbal aspects were observed after the instillations of PBS, travoprost/ timolol $\mathrm{PQ}$, and travoprost/timolol BAK (Figures 3A-C and 4A-C). Obvious inflammatory 
Figure 4. At day 1 (D1) the corneal in-vivo confocal microscopy (IVCM) images of the rabbit corneal epithelium (line 1), basal epithelium (line 2), limbus (line 3), and conjunctiva-associated lymphoid tissue (CALT) (line 4 ) after the applications of (A) phosphate-buffered saline (PBS), (B) travoprost/timolol polyquarternium (PQ), (C) travoprost/timolol benzalkonium chloride (BAK), and (D) latanoprost/timolol BAK.

\begin{tabular}{|c|c|c|c|c|}
\hline & (A) & $\begin{array}{c}\text { (B) } \\
\text { Travoprost/ } \\
\text { timolol PQ }\end{array}$ & $\begin{array}{c}(\mathrm{C}) \\
\text { Travoprost/ } \\
\text { timolol BAK } \\
0.015 \%\end{array}$ & $\begin{array}{c}(\mathrm{D}) \\
\text { Latanoprost/ } \\
\text { timolol BAK } \\
0.02 \%\end{array}$ \\
\hline \multicolumn{5}{|l|}{ Line 1} \\
\hline \multicolumn{5}{|c|}{ Superficial epithelium } \\
\hline \multicolumn{5}{|l|}{ Depth: $0 \mu \mathrm{m}$} \\
\hline \multicolumn{5}{|l|}{ Line 2} \\
\hline \multicolumn{5}{|l|}{ Basal epithelium } \\
\hline \multicolumn{5}{|l|}{ Depth: $10-15 \mu \mathrm{m}$} \\
\hline \multicolumn{5}{|l|}{ Line 3} \\
\hline \multicolumn{5}{|l|}{ Limbus } \\
\hline \multicolumn{5}{|l|}{ Depth: $10-30 \mu \mathrm{m}$} \\
\hline \multicolumn{5}{|l|}{ Line 4} \\
\hline \multicolumn{5}{|l|}{ CALT } \\
\hline \multicolumn{5}{|l|}{ Depth: $0-15 \mu \mathrm{m}$} \\
\hline
\end{tabular}

infiltrations in the peripheral cornea and limbus area were found after instillation of latanoprost/timolol BAK (Figure 3D). This infiltration persisted at D1 (Figure 4D), but at a decreased level.

\section{CALT}

At H4, after instillation of PBS or travoprost/ timolol PQ, the CALT follicles were inactive, without any obvious inflammatory infiltration inside and outside of the follicle (Figure 3A-B). In contrast, following instillation of travoprost/ timolol BAK or latanoprost/timolol BAK, obvious increases of high levels of inflammatory cell infiltration were observed especially outside the CALT follicle (Figure 3C-D). At D1, the inflammatory cell infiltration decreased but persisted for both the travoprost/timolol BAK and latanoprost/timolol BAK groups (Figure 4C-D).

\section{IVCM Scale Score}

An IVCM scale score was used to quantify the cytotoxic reactions according to the degree of ocular surface damage (Figure 5). At H4 and D1, PBS and travoprost/timolol PQ instillations produced 
Figure 5. In-vivo confocal microscopy (IVCM) scores (mean \pm standard error $[\mathrm{SEM}]$ ) for total ocular surface toxicity at hour 4 (H4) and day 1 (D1) in rabbit eyes $(n=6$ eyes/time point). Refer to Table 1 for scoring. *Statistically significant vs. phosphate-buffered saline (PBS) (travoprost/ timolol benzalkonium chloride $[\mathrm{BAK}]): \mathrm{H} 4, P=0.044$; D1, $P=0.012$; latanoprost/timolol BAK: H4, $P<0.0001$ and $\mathrm{D} 1, P=0.0001)$. + Statistically significant vs. travoprost/ timolol polyquarternium (PQ) (travoprost/timolol BAK: H4, $P=0.028$; D1, $P=0.037$; latanoprost $/$ timolol BAK: H4 and D1, $P<0.0003) . ~ \neq P<0.02$ vs. latanoprost/timolol BAK.

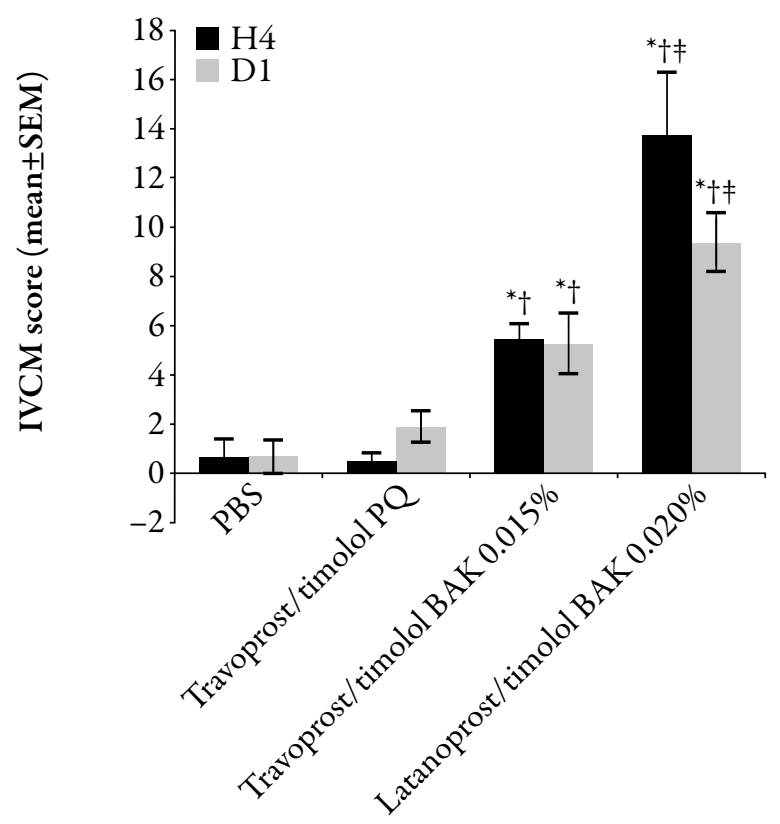

low IVCM toxicity scores, and there was no significant difference between them. Travoprost/ timolol PQ produced significantly lower total ocular toxicity scores than latanoprost/timolol BAK $(P<0.0003$ at $\mathrm{H} 4$ and D1) and travoprost/ timolol BAK $(P=0.044$ at $\mathrm{H} 4$, and $P=0.012$ at D1). Compared with the other treatments, travoprost/ timolol BAK presented a moderately high IVCM score, which was significantly less than the latanoprost/timolol BAK score $(P<0.02$ at $\mathrm{H} 4$ and D1), but significantly greater than the scores produced by $\mathrm{PBS}(P=0.044$ at $\mathrm{H} 4$, and $P=0.012$ at D1) and travoprost/timolol PQ $(P=0.044$ at $\mathrm{H} 4$, and $P=0.012$ at D1).
Figure 6. Superficial conjunctival cell changes at hour 4 (H4) after repeated instillations of eye drops, as measured with impression cytology staining with cresyl violet. Images taken with an objective lens $\times 20$. (A) Phosphate-buffered saline (PBS): clearly visible goblet cells; (B) travoprost/ timolol polyquarternium (PQ): homogeneous, slightly metaplastic epithelium with normal goblet cells; (C) travoprost/timolol benzalkonium chloride (BAK): numerous inflammatory cells, conjunctival epithelial cells with abnormal desquamation, swelling, and anisocytosis; and (D) latanoprost/timolol BAK: numerous inflammatory cells, conjunctival epithelial cells with abnormal desquamation, swelling, and anisocytosis.
(A)

PBS

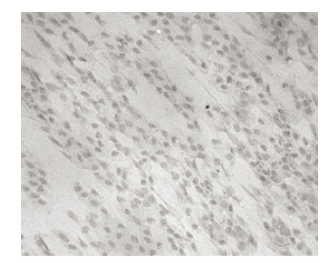

(C)

Travoprost/timolol BAK $0.015 \%$

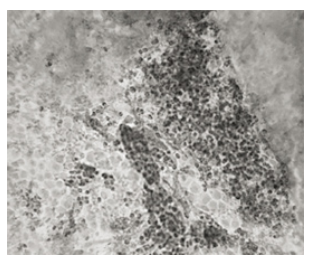

(B) Travoprost/timolol PQ

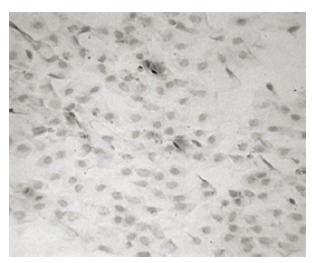

(D) BAK $0.02 \%$

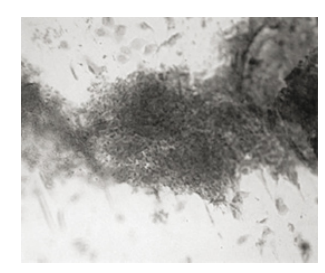

\section{Impression Cytology Staining}

At H4, eyes instilled with PBS had normal, polyhedral conjunctival epithelium with goblet cells (Figure 6A). The eyes instilled with travoprost/timolol PQ presented a homogeneous, slightly metaplastic epithelium with normal goblet cells (Figure 6B). Eyes instilled with travoprost/timolol BAK (Figure 6C) or latanoprost/timolol BAK (Figure 6D) were infiltrated with numerous inflammatory cells, principally consisting of polynuclear cells, and also lymphocytes. Further, the impression cytology showed that the conjunctival epithelial 
Figure 7. Superficial conjunctival cell changes at day 1 (D1) after repeated instillations of eye drops, as measured with impression cytology staining with cresyl violet. Images taken with an objective lens $\times 20$. (A) Phosphate-buffered saline (PBS): normal epithelium, visible goblet cells; (B) travoprost/timolol polyquarternium (PQ): normal epithelium, visible goblet cells; (C) travoprost/timolol benzalkonium chloride (BAK): inflammatory infiltration; and (D) latanoprost/timolol BAK: inflammatory infiltration.

(A) PBS

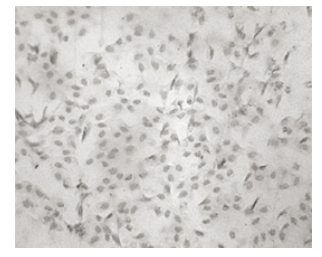

(C)

Travoprost/timolol BAK $\mathbf{0 . 0 1 5 \%}$

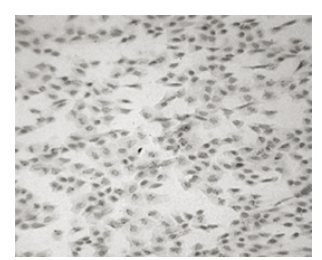

(B)

Travoprost/timolol PQ

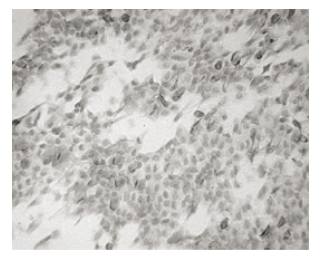

(D)

Latanoprost/timolol BAK $0.02 \%$

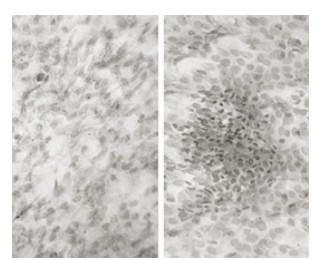

Figure 8. Conjunctival impression cytology scores (Nelson scoring, mean \pm standard error $[S E M]$ ), evaluating epithelium aspects, goblet cells, and inflammatory infiltration level, at hour 4 (H4) and day 1 (D1) in rabbit eyes $\left(n=6\right.$ eyes/time point). ${ }^{*}$ Statistically significant vs. phosphate-buffered saline (PBS) (travoprost/timolol benzalkonium chloride [BAK]: $P<0.02$, latanoprost/ timolol BAK: $P<0.0005$ at H4). † Statistically significant vs. travoprost/timolol polyquarternium (PQ) (travoprost/ timolol BAK: $P<0.02$, latanoprost/timolol BAK: $P<0.0005$ at $\mathrm{H} 4)$.

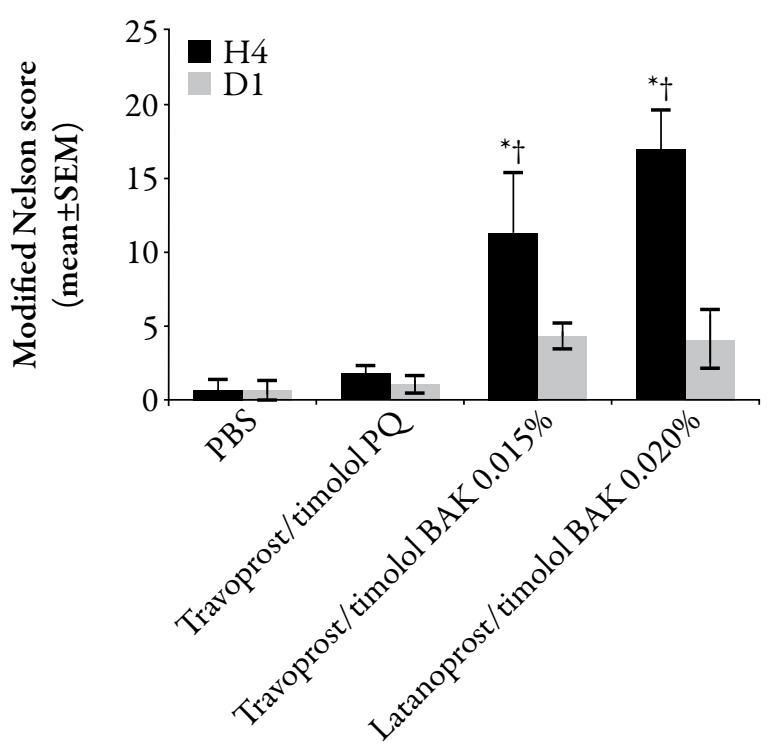

image information, including conjunctival epithelium aspects, goblet cell presentation, and inflammatory infiltration level. At $\mathrm{H} 4$ and D1, eyes treated with PBS or travoprost/ timolol PQ had low Nelson scores, which were not significantly different from each other. At H4, latanoprost/timolol BAK $(P<0.0005)$ and travoprost/timolol BAK $(P<0.02)$ had significantly higher Nelson scores than PBS or travoprost/ timolol PQ, which is attributed to the associated inflammatory infiltration and conjunctival epithelium damage. At D1, the inflammatory infiltration associated with latanoprost/timolol BAK and travoprost/timolol BAK decreased. Accordingly, there were no significant differences between the four treatment groups (Figure 8). 
Figure 9. Immunostaining of CD 45+ cells (green) in cornea cryosections (images taken with an objective lens $\times 10$ ) at hour 4 (H4). (A) Phosphate-buffered saline (PBS): few CD45+ cells; (B) travoprost/timolol polyquarternium (PQ): few CD45+ cells; (C) travoprost/timolol benzalkonium chloride (BAK): moderate amount of CD45+ cells; (D) latanoprost/ timolol BAK: large amount of CD 45+ cells; (E) CD45+ inflammatory cell counts (mean \pm standard deviation [SEM]) in cornea at $\mathrm{H} 4$ and day 1 (D1) ( $n=6$ eyes/time point). * Statistically significant vs. PBS (travoprost/timolol BAK: H4, $P<0.0001$; D1, $P=0.0002$; latanoprost/timolol BAK: H4 and D1, $P<0.0001)$. † Statistically significant vs. travoprost/ timolol PQ (travoprost/timolol BAK: H4 and D1, $P<0.0001$; latanoprost/timolol BAK: H4 and D1, $P<0.0001$ ). $\neq \mathrm{H} 4$, $P=0.0006$ vs. travoprost/timolol BAK.

(A)

PBS

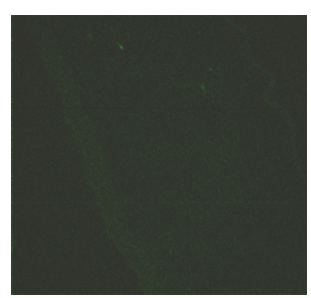

(C)

Travoprost/timolol BAK 0.015\%

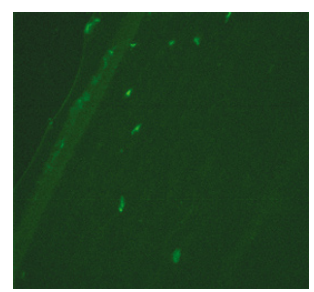

(B)

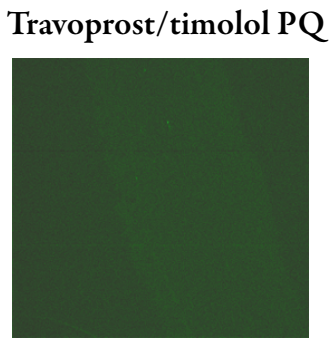

(D)

Latanoprost/timolol BAK $0.02 \%$

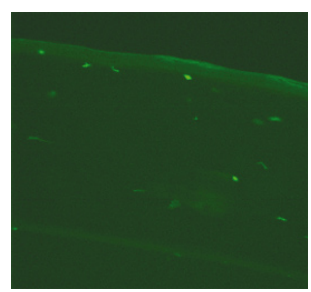

(E)

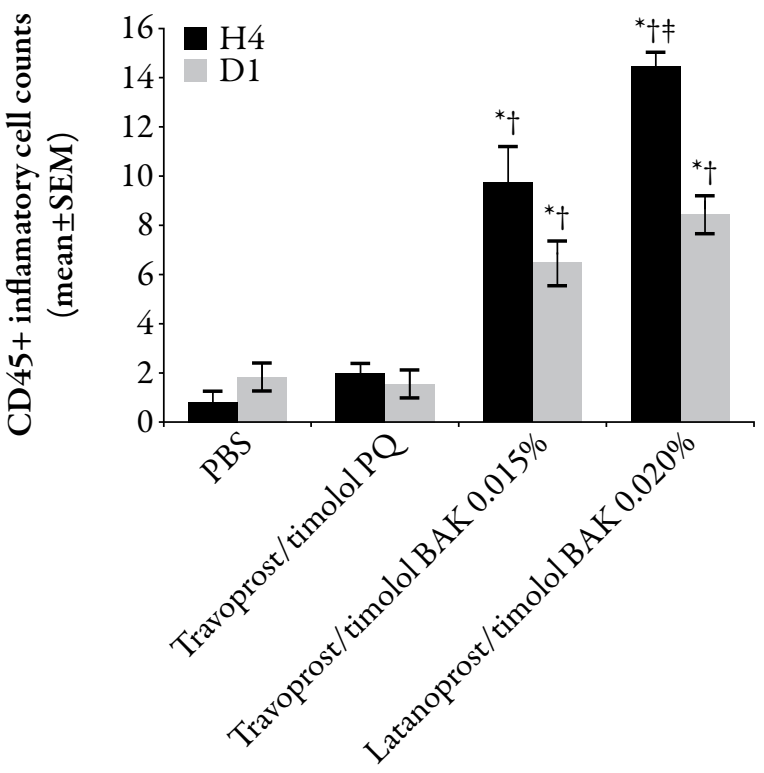

for both) and travoprost/timolol PQ $(P<0.0001$ for both). Travoprost/timolol BAK also induced significantly fewer CD45+ cells than latanoprost/timolol BAK $(P<0.0006)$.

At D1, both PBS and travoprost/timolol PQ induced less than two cells/field; there was no significant difference between the groups. Travoprost/timolol BAK and latanoprost/ timolol BAK continued to have moderate levels of CD45+ cells in the cornea (for travoprost/ timolol BAK, $P=0.0002$ when compared with PBS and $P<0.0001$ when compared with travoprost/ timolol PQ groups; for latanoprost/timolol BAK, $P<0.0001$ when compared with PBS and travoprost/timolol PQ). 
Figure 10. Immunostaining of MUC-5AC+ mucocyte cells (green) in conjunctiva cryosections (images taken with an objective lens $\times 10$ ) at hour $4(\mathrm{H} 4)$. (A) Phosphate-buffered saline (PBS): normal distribution of goblet cells; (B) travoprost/ timolol polyquarternium (PQ): normal, homogeneous distribution of goblet cells; (C) travoprost/timolol benzalkonium chloride (BAK): decreased goblet cell density; (D) latanoprost/timolol BAK: decreased goblet cell density; (E) MUC$5 \mathrm{AC}+$ mucocytes in the conjunctiva at $\mathrm{H} 4$ and day 1 (D1) $\left(n=6\right.$ eyes/time point). ${ }^{*}$ Statistically significant vs. PBS (travoprost/timolol BAK: H4, $P<0.006$; D1, $P<0.02$; latanoprost/timolol BAK: H4, $P<0.007$ and D1, $P<0.003$ ). † Statistically significant vs. travoprost/timolol PQ (travoprost/timolol BAK: H4, $P<0.0003$; D1, $P<0.0008$; latanoprost/ timolol BAK: H4, $P<0.0004$ and D1, $P<0.0001)$.

(A)

PBS

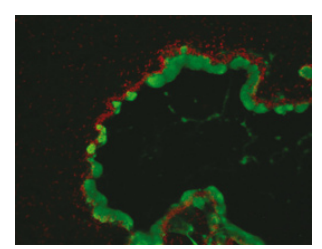

(C)

Travoprost/timolol

BAK 0.015\%

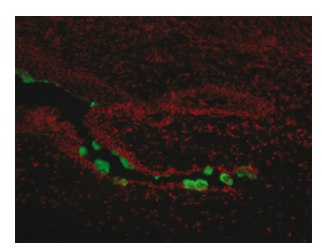

(B)

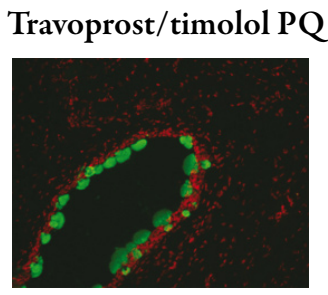

(D)

Latanoprost/timolol

BAK 0.02\%

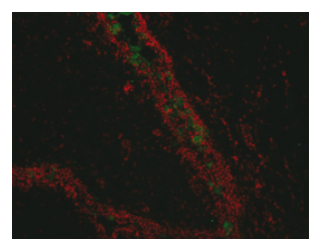

(E)

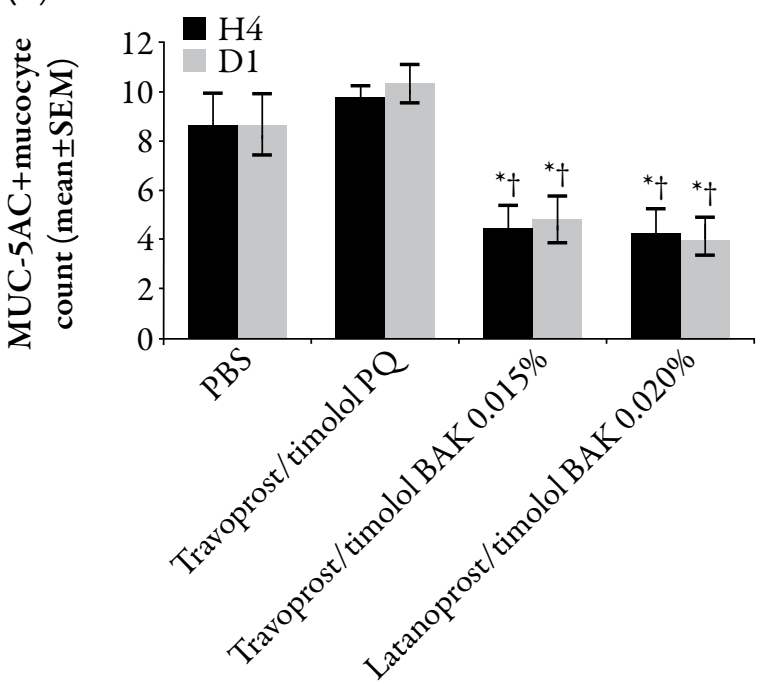

\section{Immunostaining of MUC-5AC+}

Immunostaining against MUC-5AC+ goblet cells in rabbit cryosections is shown in Figure 10A$\mathrm{D}$, and cell counts are presented in Figure 10E. The normal goblet cells appear as green, round patterns with a homogeneous distribution. At H4, PBS instillation clearly maintained normal aspects and distribution of goblet cells in the superficial layer of conjunctiva, with a mean of 8.17 cells/field. Travoprost/timolol PQ had a mean of 9.83 cells/field, which was not significantly different from PBS. For travoprost/ timolol BAK and latanoprost/timolol BAK, obvious decreases of goblet cell number and goblet cell size were found with respective mean counts of 4.5 cells/field and 4.33 cells/field (respectively $P<0.006$ and $P<0.007$ vs. $P B S$ and $P<0.0003$ and $P<0.0004$ vs. travoprost/ timolol PQ).

The goblet cell findings at D1 were similar to H4. Eyes instilled with PBS or travoprost/ timolol PQ presented with normal goblet cell counts: 8.67 cells/field and 10.33 cells/field, respectively. Travoprost/timolol BAK and latanoprost/timolol BAK instillation clearly damaged the goblet cells. There was a significant decrease in goblet cell counts with travoprost/timolol BAK-instilled eyes having 4.83 cells/field $(P<0.02$ vs. $P B S$ and $P<0.0008$ vs. travoprost/timolol PQ) and latanoprost/timolol BAK-instilled eyes having 4.13 cells/field $(P<0.003$ vs. $P B S$ and $P<0.0001$ vs. travoprost/ timolol PQ). 


\section{DISCUSSION}

The aim of this in-vivo, repeated dosing, acute instillation model was to distinguish the ocular surface toxicity level of different eye drops. The dosing does not mimic real life and would be considered overdosing in humans; however, it is a good model to evaluate toxicity. After instilling the drops 15 times in rabbits, the newly developed travoprost/timolol PQ was better tolerated than the commercially available travoprost/ timolol BAK and latanoprost/timolol BAK. This improved tolerance was evident not only via clinical observation under slit lamp, but also by IVCM in the different layers of the cornea and conjunctiva, by CIC for superficial epithelium aspects, and by immunohistochemistry for inflammatory infiltration of CD45+ cells in the cornea and goblet cell distribution. Indeed, instillation of travoprost/timolol PQ was similar to instillation of PBS in regards to the in-vivo findings, the Draize test for ocular irritation, and epithelial and limbal aspects as evaluated with IVCM. Furthermore, instillation with either travoprost/timolol PQ or PBS produced no obvious inflammatory infiltration inside and outside the CALT follicles, yielded similar IVCM toxicity scores and CD45+ cell counts, and eyes treated with either solution had normal goblet cell presentation.

The findings from this in-vivo study support the results of earlier in-vitro studies. One in-vitro study compared the cytotoxicity of travoprost/timolol PQ, travoprost/ timolol BAK, and latanoprost/timolol BAK in several assays of cell viability, apoptosis, and oxidative stress. ${ }^{21}$ Cultured human conjunctival epithelial cells incubated with travoprost/timolol PQ had significantly better cell viability and significantly less evidence of apoptosis than cells incubated with travoprost/timolol BAK or latanoprost/timolol BAK. ${ }^{21}$ Also, travoprost/timolol PQ produced significantly less induction of oxidative stress than latanoprost/timolol BAK. ${ }^{21}$ Similarly, in another in-vitro study, exposure to travoprost ophthalmic solution preserved with BAK yielded statistically more live epithelial and corneal cells in culture than cells exposed to BAK alone. ${ }^{22}$ Also, travoprost ophthalmic solution preserved with PQ was statistically less toxic to corneal and conjunctival cells in culture than travoprost ophthalmic solution preserved with BAK. ${ }^{22}$ Similarly, in the present study travoprost/timolol PQ produced a significantly lower total ocular toxicity score than travoprost/timolol BAK and latanoprost/ timolol BAK in vivo. Also, travoprost/timolol BAK and latanoprost/timolol BAK induced damage to the surface epithelium; showing partial desquamation, abnormal reflectivity patterns, and anisocytosis with irregular cell shape. In contrast, rabbit eyes treated with travoprost/timolol PQ were similar to PBS and the cells of the surface epithelium were of normal shape and size.

A limitation of this study is that the drugs were not compared with their respective antimicrobial preservatives. In a previous study with the same experimental design BAK $0.015 \%$ and PQ $0.001 \%$ control groups were included. ${ }^{13}$ The study revealed that rabbit eyes treated with PQ $0.001 \%$ had no obvious ocular surface irritation or changes in microstructures of the whole ocular surface, no inflammatory infiltration, or cell damage as measured by impression cytology, no altered levels of goblet cell counts, and few CD45+ cells in the cornea. ${ }^{13}$ In contrast, rabbit eyes treated with BAK $0.015 \%$ induced diffuse hyperemia and chemosis on the conjunctiva, abnormal changes in the ocular surface microstructure, significant 
ocular surface toxicity, epithelial cell damage, inflammatory cell infiltration, decreased goblet cell density, and significantly more CD45+ cells in the cornea than PQ $0.001 \% .{ }^{13}$

\section{CONCLUSION}

The in-vivo and in-vitro analyses of the novel formulation of travoprost/timolol PQ indicate that replacing BAK with PQ has the potential to produce clinically beneficial outcomes. The benefit to the human ocular surface needs to be evaluated clinically. However, it is obvious that compared with concomitant dosing, fixed combinations of ophthalmic medications decrease the exposure to the toxic preservative BAK, and the fixed combination of travoprost/ timolol PQ with $0.001 \%$ PQ could further decrease the cytotoxicity and risk of ocular surface disease by eliminating ocular exposure to BAK. Clinical studies are needed to confirm these findings in patients with ocular hypertension or open-angle glaucoma.

\section{ACKNOWLEDGMENTS}

Writing assistance was provided by Heather S. Oliff, PhD of Science Consulting Group, LLC, North Tustin, CA. The data have been presented at the European Glaucoma Society (EGS), Sept 12, 2010, Madrid, Spain, and at the European Association for Vision and Eye Research (EVER), Oct 6, 2010, Creta, Greece. The authors have no commercial interest in the drugs mentioned in the manuscript. This study was sponsored by an unrestricted grant from Alcon Research Inc., Fort Worth, TX, USA. The research group in the Vision Institute, to which F.B.-B., L.R., H.L., A.P., and C.B. belong, has received research grants from Alcon, Allergan, Pfizer, MSD, Thea, and Santen. C.B. is or has been a consultant for Alcon, Allergan, Pfizer, MSD, Thea, and Santen.
C.B. is the guarantor for this article, and takes responsibility for the integrity of the work as a whole.

Open Access. This article is distributed under the terms of the Creative Commons Attribution Noncommercial License which permits any noncommercial use, distribution, and reproduction in any medium, provided the original authors and source are credited.

\section{REFERENCES}

1. Schmier JK, Covert DW, Robin AL. Estimated firstyear costs of prostaglandin analogs with/without adjunctive therapy for glaucoma management: a United States perspective. Curr Med Res Opin. 2007;23:2867-2875.

2. Schmier JK, Covert DW, Robin AL. First-year treatment patterns among new initiators of topical prostaglandin analogs. Curr Med Res Opin. 2009;25:851-858.

3. Robin AL, Novack GD, Covert DW, Crockett RS, Marcic TS. Adherence in glaucoma: objective measurements of once-daily and adjunctive medication use. Am J Ophthalmol. 2007;144:533540 .

4. Baudouin C. The ocular surface in glaucoma. Cornea. 2009;28:S14-S19.

5. Baudouin C, Labbe A, Liang H, Pauly A, BrignoleBaudouin F. Preservatives in eyedrops: the good, the bad and the ugly. Prog Retin Eye Res. 2010;29:312334.

6. Baudouin C, Pisella PJ, Fillacier K, et al. Ocular surface inflammatory changes induced by topical antiglaucoma drugs. Ophthalmology. 1999;106:556-563.

7. Pisella PJ, Pouliquen P, Baudouin C. Prevalence of ocular symptoms and signs with preserved and preservative free glaucoma medication. $\mathrm{Br} \mathrm{J}$ Ophthalmol. 2002;86:418-423.

8. Leung EW, Medeiros FA, Weinreb RN. Prevalence of ocular surface disease in glaucoma patients. J Glaucoma. 2008;17:350-355.

9. Fechtner RD, Godfrey DG, Budenz D, Stewart JA, Stewart WC, Jasek MC. Prevalence of ocular surface 
complaints in patients with glaucoma using topical intraocular pressure-lowering medications. Cornea. 2010;29:618-621.

10. Labbe A, Pauly A, Liang $\mathrm{H}$, et al. Comparison of toxicological profiles of benzalkonium chloride and polyquaternium-1: an experimental study. J Ocul Pharmacol Ther. 2006;22:267-278.

11. Lipener C. A randomized clinical comparison of OPTI-FREE EXPRESS and ReNu MultiPLUS multipurpose lens care solutions. Adv Ther. 2009;26:435-446.

12. Whitson JT, Ochsner KI, Moster MR, et al. The safety and intraocular pressure-lowering efficacy of brimonidine tartrate $0.15 \%$ preserved with polyquaternium-1.Ophthalmology.2006;113:13331339.

13. Liang $\mathrm{H}$, Brignole-Baudouin $\mathrm{F}$, Riancho $\mathrm{L}$, Baudouin C. In vivo assessment of the ocular surface effects of travoprost BAK-free versus BAKpreserved travoprost and latanoprost ophthalmic solutions. Paper presented at: Tear Film \& Ocular Surface, Florence, Italy, September 22-25, 2010,.

14. Lopez Bernal D, Ubels JL. Quantitative evaluation of the corneal epithelial barrier: effect of artificial tears and preservatives. Curr Eye Res. 1991;10:645656.

15. Ichijima H, Petroll WM, Jester JV, Cavanagh HD. Confocal microscopic studies of living rabbit cornea treated with benzalkonium chloride. Cornea. 1992;11:221-225.

16. Liang H, Baudouin C, Faure MO, Lambert G, Brignole-Baudouin F. Comparison of the ocular tolerability of a latanoprost cationic emulsion versus conventional formulations of prostaglandins: an in vivo toxicity assay. Mol Vis. 2009; 15:1690-1699.

17. Liang H, Baudouin C, Pauly A, Brignole-Baudouin F. Conjunctival and corneal reactions in rabbits following short- and repeated exposure to preservative-free tafluprost, commercially available latanoprost and $0.02 \%$ benzalkonium chloride. $\mathrm{Br} \mathrm{J}$ Ophthalmol. 2008;92:1275-1282.

18. Liang H, Brignole-Baudouin F, Rabinovich-Guilatt L, et al. Reduction of quaternary ammonium-induced ocular surface toxicity by emulsions: an in vivo study in rabbits. Mol Vis. 2008;14:204-216.

19. Brignole-Baudouin F, Ott AC, Warnet JM, Baudouin C. Flow cytometry in conjunctival impression cytology: a new tool for exploring ocular surface pathologies. Exp Eye Res. 2004;78:473-481.

20. Haller-Schober EM, Schwantzer G, Berghold A, Fischl M, Theisl A, Horwath-Winter J. Evaluating an impression cytology grading system (IC score) in patients with dry eye syndrome. Eye. 2006;20:927933.

21. Brignole-Baudouin F, Riancho L, Liang $H$, Baudouin C. In vitro comparative toxicology of BAK-free and BAK-preserved travoprost/timolol fixed combination and latanoprost/timolol fixed concentration. J Ocul Pharmacol Ther. In press.

22. Ammar DA, Noecker RJ, Kahook MY. Effects of benzalkonium chloride-preserved, polyquadpreserved, and sofZia-preserved topical glaucoma medications on human ocular epithelial cells. Adv Ther. 2010;27:837-845. 